\title{
Grecia: una odisea económica reciente
}

\section{Valeria Ivett Luna Flores* y Rómulo Daniel Montes de Oca Zárate**}

Durante los últimos años Grecia ha pasado a ser una de las economías europeas vulneradas por los desajustes globales, los cuales comenzaron a raíz de la recesión económica de los Estados Unidos en 2008, mientras que para Europa se intensificaron en 2011 durante la crisis de la deuda soberana. Desde que Grecia ingresó a la Unión Europea, y más específicamente a la Unión Monetaria de esta región, existieron dudas y especulaciones respecto a los datos que el país presentó para lograr cumplir los criterios de convergencia establecidos en Maastricht. En el presente artículo se esboza un panorama de la economía griega a partir de 2011, mostrando principalmente cómo la administración griega falló en la gestión de su economía y en la correcta utilización de los recursos del rescate otorgado por la Troika. ${ }^{1}$ Por otra parte se buscará realizar un breve análisis sobre los signos vitales del sector financiero de este país, a raíz de los desajustes estructurales de su economía.

\section{El problema de la deuda}

El rescate de Grecia por parte de la Troika empezó en mayo de 2010 cuando se le otorga un primer préstamo de aproximadamente $240 \mathrm{mil}$

${ }^{1}$ Compuesta por el Fondo Monetario Internacional (FMI), el Banco Central Europeo (BCE) y la Comisión Europea (CE). millones de euros, dado que en octubre de 2009 se descubren las verdaderas cifras del nivel de la deuda pública de Grecia; además de este préstamo ha habido otros con las mismas condiciones, es decir, sujetos a hacer ajustes estructurales como son la disminución de los salarios de los funcionarios y la eliminación de las primas anuales, los aumentos del IVA, la puesta en vigor de nuevos impuestos, las privatizaciones, se dejaron de dar contratos con los beneficios de las reglamentaciones colectivas ${ }^{2}$ y se dio preferencia a los contratos individuales. ${ }^{3}$ El salario mínimo bruto nacional disminuyó, pasando de 751 euros a 580 euros, un decremento del $22 \%$.

El segundo plan de ayuda consistió en reducciones de las tasas de interés de la deuda soberana que tenía el sector privado. A partir del año 2012 Grecia se ha visto beneficiada porque ha obtenido una prórroga de 10 años para pagar sus intereses con respecto a los préstamos del instrumento European Financial Stability Facility (EFSF) y en ese mismo año se canceló la mitad

${ }^{2}$ Reglamentación colectiva son textos reglamentarios donde se definen todos los derechos de los trabajadores en función de la rama profesional; surgen de negociaciones entre los sindicatos y los empresarios; las reglamentaciones colectivas aseguran un aumento de sueldo para todos los trabajadores.

${ }^{3}$ Donde la negociación de las condiciones de trabajo se hace únicamente entre la empresa y el empleado sin las ventajas de beneficiarse de aumentos de sueldos generalizados por ejemplo.

* Estudiante de la especialización en Economía Monetaria y Financiera, FE-UNAM. Titular de un DEA y Doctorado en Economía Bancaria por la Universidad de Paris X, Nanterre.

** Miembro del Seminario de Credibilidad Macroeconómica, FE-UNAM. 
de la deuda griega acumulada hasta esta fecha. En abril 2015 el país regresó a los mercados de deuda soberana después de 4 años sin haber emitido deuda; esta emisión de deuda griega fue a mediano plazo. El FMI mantiene todavía un acuerdo para financiar a Grecia hasta el año 2016. La Comisión Europea decidió dar más ayuda a Grecia, por lo cual se le hizo una auditoria a este país en febrero de 2015. Grecia aceptó que la Troika llevará a cabo una auditoria sobre su situación financiera y la de sus prestamistas. Después de esta auditoria a finales de marzo del 2015 la Comisión Europea examinó las reformas propuestas por el gobierno del presidente Alexis Tsipras, y éstas fueron aprobadas por lo que se le dio una ayuda de aproximadamente 7 mil millones de euros a Grecia para que así pudiera rembolsar al FMI. Dentro de estas reformas hay 20 medidas algunas de las cuales tendrán como resultado final un aumento de los impuestos, principalmente destinados a la gente más rica.

Los intereses que Grecia devengará por concepto de su deuda rondan el 2\% del PIB, lo cual representa un nivel bajo; este nivel tan bajo fue posible porque los prestamistas dieron una prórroga antes de que los intereses empezasen a ser pagados (Wolff, 2015). El país mediterráneo se ha visto beneficiado con disminuciones en las tasas de interés a las cuales debe de pagar su deuda y mayores plazos de vencimiento de los préstamos.

Los gobiernos de la Zona Euro, principalmente Alemania y Francia, le han prestado 195 mil millones de euros, además Grecia recibió una ayuda de 32 mil millones de euros de la parte del FMI. Alemania es el país con mayor tenencia de deuda griega dentro de sus activos, ya que le ha prestado 56 mil millones de euros, mientras que Francia ha dirigido 42 mil millones de euros a esta economía. Los préstamos europeos otorgados a Grecia tienen un plazo de 30 años y las tasas de interés sobre estos préstamos son muy bajas, en promedio inferiores a $1 \%$. Además, los intereses de los títulos griegos que el BCE tiene en su poder, se le pagan a Grecia para ayudarla.

\section{Panorama actual}

Los principales ingresos del país provienen de su gran actividad del transporte marítimo, agricultura, servicios y turismo, hay poca industria y tienen exportaciones con muy poca tecnología principalmente productos alimentarios dado que es el tercer productor a nivel mundial de aceitunas, además exporta químicos, metales y petróleo refinado. Su nulo desarrollo del sector servicios lo coloca como un demandante neto de estos en el exterior; por su parte el pequeño peso relativo de Grecia en la economía eu- 


\section{Cuadro I}

Grecia: indicadores económicos, 2012 - 2015

\begin{tabular}{|l|r|r|r|r|}
\hline \multicolumn{1}{|c|}{ Indicador/Años } & $\mathbf{2 0 1 2}$ & $\mathbf{2 0 1 3}$ & $\mathbf{2 0 1 4 ^ { \mathrm { e } }}$ & $\mathbf{2 0 1 5}^{\mathrm{p}}$ \\
\hline$\Delta(\%)$ PIB & -6.6 & -4 & -0.8 & 2.3 \\
\hline Inflación (promedio anual) & 1 & -0.9 & -1.1 & n.d \\
\hline Balance presupuestario* & -8.6 & -12.2 & -1.0 & -0.05 \\
\hline Cuenta corriente* & -2.4 & -0.6 & 1.2 & 1 \\
\hline Deuda pública* & 156.8 & 175.1 & 176.1 & 174.3 \\
\hline
\end{tabular}

*porcentaje del PIB, ${ }^{\mathrm{e}}$ estimaciones, ${ }^{\mathrm{p}}$ pronósticos.

Fuente: COFACE, 2015.

ropea lo sitúa en una posición vulnerable dentro de las negociaciones dentro de la comunidad.

Las elecciones de 2014 se adelantaron en Grecia y tuvieron lugar el 17 de diciembre. Previo a las elecciones el partido que estaba en el poder era el partido de la Nueva Democracia, un partido de derecha conservadora. Las elecciones legislativas anticipadas tuvieron lugar el 25 de enero de 2015, en las cuales se dio un cambio; a partir de estas elecciones el gobierno se integra de un partido de la izquierda estadista Syriza y está aliado con el Partido de los Griegos Independientes. Este nuevo gobierno pide que se extienda el plazo de rembolso de Grecia; a finales del año 2014 la deuda total pública griega era igual a 320 miles de millones de euros cerca del 176\% del PIB y también este nuevo gobierno desea que Grecia ya no esté sujeta a los programas de austeridad impuestos por la Troika. El nuevo gobierno se propone encontrar una solución a la evasión de impuestos y a la corrupción y quiere en este año que el salario regrese a su nivel anterior de 751 euros, a principios de 2015 el salario vigente es de 580 euros al mes.

Dados los datos del Cuadro 1, la calificación que la consultora COFACE le da a Grecia en relación al riesgo país es de c. Dentro de los planes de austeridad se da un aumento de algunos impuestos, por ejemplo: los impuestos a las clases medias aumentaron significativamente; las clases medias han sido quienes más impuestos han pagado ya que la gente rica ha encontrado la forma de abrir cuentas en paraísos fiscales. Todavía no ha podido encontrarse una solución al problema de la evasión fiscal. Al mismo tiempo que han aumentado los impuestos han disminuido los ingresos de la clase media. Muchos hogares ya no pueden pagar los impuestos ni rembolsar los préstamos inmobiliarios, créditos con tarjetas de crédito y créditos otorgados a las empresas. Muchas pequeñas empresas han tenido que cerrar. Otra de las debilidades 


\section{Gráfica I}

Grecia: indicador compuesto de estrés sistémico, 2000-2014

- frecuencia mensual -

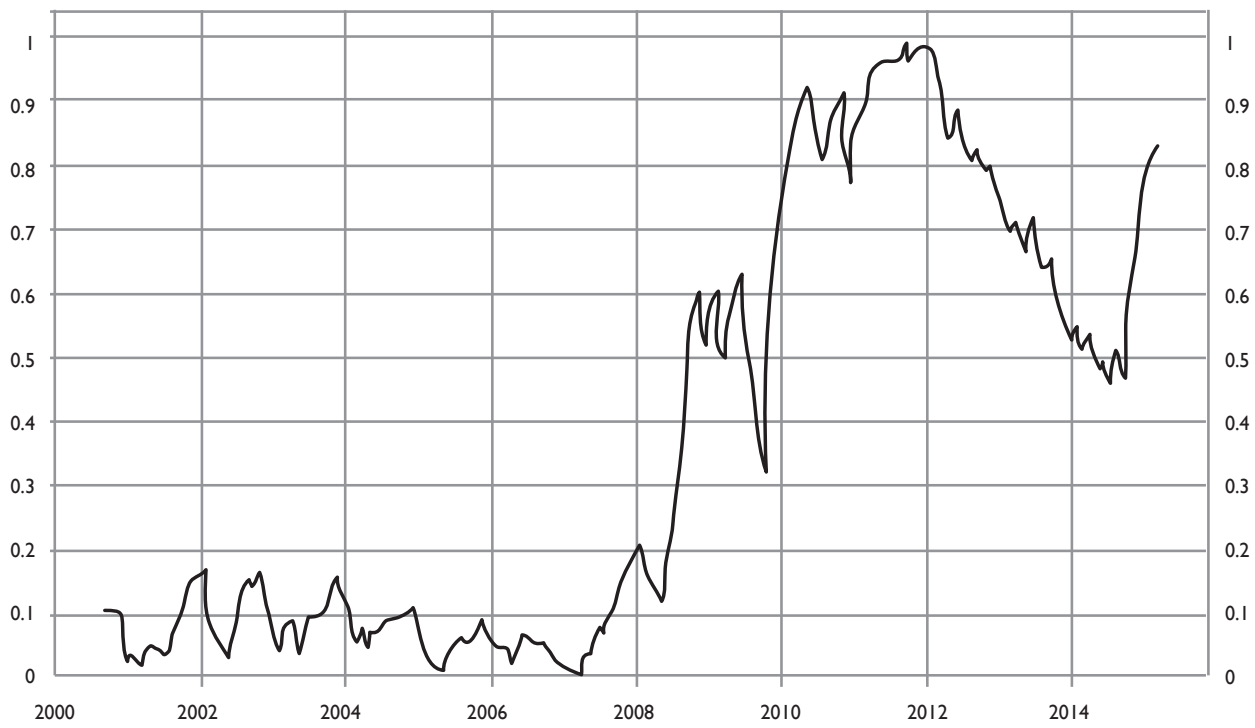

Fuente: BCE, otros indicadores.

de la economía de Grecia es que no ha habido ninguna reforma fiscal coherente y consistente.

La deflación dentro de la economía griega podría traducirse en una cuestión de seguridad económica para las familias griegas en general, ya que el mayor enfriamiento de su economía se traduciría en un mayor desempleo generando un mayor descontento social, destruyendo casi por completo la confianza restante que existe dentro del país mediterráneo. Pese a que el panorama económico mundial muestra un ligero apaciguamiento respecto a las turbulencias presentes a finales de la primera década del siglo XXI, es prioritario para la economía griega recobrar la confian- za sobre sus capacidades de pago y sobre el cumplimiento de los compromisos que ha tomado como parte de los programas de rescate; mientras los miembros de la Comunidad Económica Europea y del sector financiero ven a Grecia como un país moroso, la recuperación de esta economía seguirá un camino lento y tortuoso.

\section{El sistema financiero}

Los resultados de las pruebas de estrés del BCE muestran que los cuatro bancos con malos resultados lograron mejorar su nivel de capital a lo largo del año 2014 (COface, 2015). Para medir el riesgo sistémico el BCE publica el indicador compuesto de estrés 
sistemático CISs, el cual permite medir algunos síntomas de la estabilidad financiera, así como del estrés presente dentro de los mercados.

Como se observa en la Gráfica 1, el CISs ${ }^{4}$ que refleja el estrés sistemático de la economía griega presenta un alza significativa desde el año 2008; debido al resquebrajamiento generalizado del sistema financiero global así como el deterioro de las condiciones crediticias derivado del pánico financiero y la desconfianza de los inversionistas. Durante el año 2011 los problemas de deuda soberana presentes en la Unión Europea se dispararon nuevamente, aunque por un período menos marcado que con el aumento original antes mencionado, ya que para principios de 2012 el nivel del indicador disminuyó considerablemente. Por su parte en octubre 2014 el indicador aumentó nuevamente. El indicador CISs tuvo un nivel de 0.8219 durante el mes de febrero 2015 y en enero su nivel fue de 0.7963 .

Ahora bien la Gráfica 2 muestra el incremento existente dentro del crédito provisto por el sector financiero durante los años de la turbulencia económica griega. Este indicador permite visualizar que el crédito proporcionado dentro de Grecia se encuentra por encima del nivel de su producto. Durante el año 2011 encontramos un máximo, donde el crédito representa 154 por ciento del producto del país, posteriormente el

\section{Gráfica 2}

Grecia: crédito doméstico provisto por el sector financiero* $2009-2013$

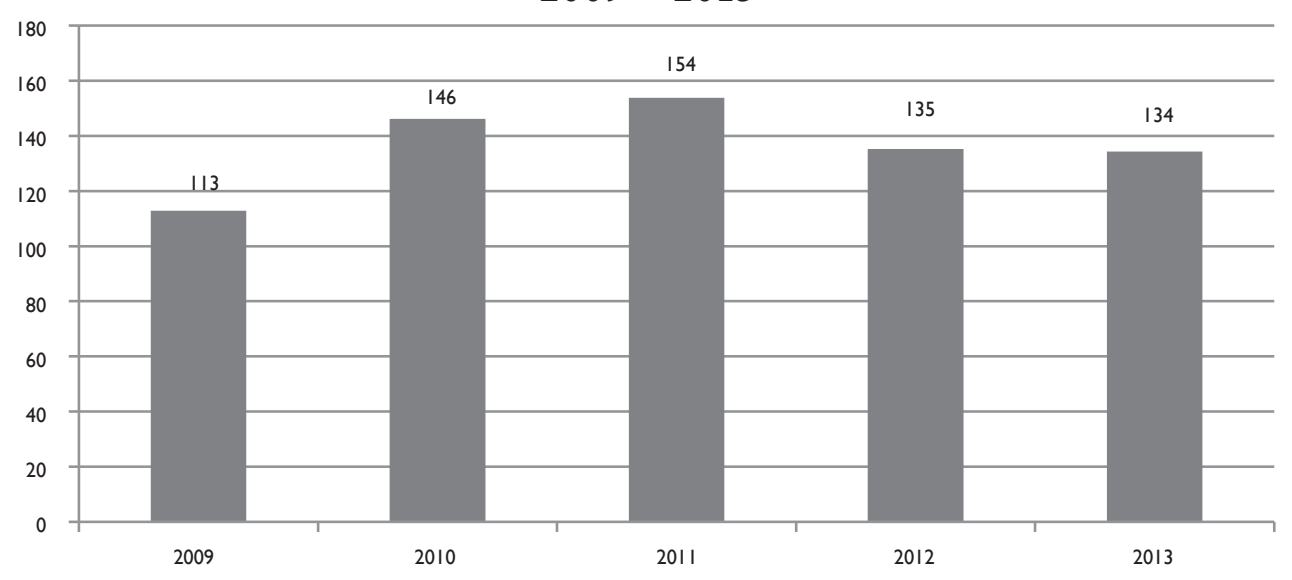

*Porcentaje del PIB.

Fuente: Banco Mundial, 2015

\footnotetext{
${ }^{4}$ Sovereign Systemic Stress Composite Indicator
} 
porcentaje de crédito en la economía comenzó a disminuir, ya que las presiones económicas desincentivaron a los prestamistas a colocar sus capitales dentro de la economía griega. A su vez la convulsión financiera generó que los requerimientos crediticios se tornarán más rígidos disminuyendo la penetración del crédito en la economía.

Los altos niveles de endeudamiento de la economía griega, por encima del total de su PIB, así como las acciones que el gobierno ha tomado dentro de la administración del capital proporcionado por la Unión Europea han hecho que la economía griega se sumerja en un esquema Ponzi de endeudamiento. A pesar de los recortes presupuestales que el programa de austeridad asumido por el gobierno helénico ha implicado, no se ha logrado reducir el endeudamiento sistemático, condición que puede empeorar si la credibilidad de los agentes en el gobierno disminuyó, generando que la tasa de interés griega se eleve y complique cada vez más la capacidad de pago del país.

\section{Conclusiones}

La relación entre la Troika y Grecia no ha permitido un avance significativo en materia de llegar a acuerdos que impulsen la implementación de reformas consistentes. La crisis grie- ga puede llevar a una crisis sistémica de la Zona Euro, hoy en día existen menos riesgos de contagio financiero debido a que la deuda griega está en manos del sector gubernamental de la Zona Euro, el BCE y el FMI a la altura del 80\% aproximadamente. La estrategia del nuevo gobierno es resolver los problemas de evasión fiscal (IVA), de comercio ilegal además se aplicarán nuevos impuestos a los juegos en línea y a los productos de lujo y la autoridad se enfocará en reformas que incentiven las privatizaciones.

Por su parte el sector financiero ha recibido una serie de choques importantes debido a que las condiciones económicas así como los problemas políticos y de estabilidad social han desalentado la inversión en los diversos sectores de la economía. La mala administración de los fondos de rescate por parte del gobierno ha afectado la imagen de Grecia como un país que no puede hacer frente a sus obligaciones y asegurar las condiciones para incentivar la inversión tanto extranjera como nacional. Toda esta situación deja abierta la solución de la economía griega, haciendo difícil el prever las condiciones de esta economía en un mediano y largo plazo. Actualmente el camino futuro de este país depende en gran medida de las decisiones políticas que aún están por verse. 


\section{Referencias}

COFACE (2015), Indicadores económicos.

Banco Central Europeo (2015), Sovereign systemic stress composite indicator.

Banco Mundial (2015), Banco de datos, Indicadores de desarrollo global.

Guillot, Adéa y Cécile Ducorutieux, (2015), "La Grèce expose ses projets de réformes", Le Monde, 28 de marzo.

Toute l'Europe (2015), “La Grèce et la France se font tirer l'oreille par l'Eurogroupe”, comunicado de prensa, Centro de Información de Europa,10 de marzo.

Wolff, Guntram (2015), “A new star for Greece”, Bruegel, febrero.

Zsolt Darvas y Huttl, Pia (2015), "How to reduce the Greek debt burden?", Bruegel, 25 de enero. 